\title{
Emerging issues in the life cycle perspective in the context of population peaking
}

\author{
Alain Bélanger ${ }^{1}$
}

\begin{abstract}
This paper proposes a theoretical examination of how taking a life cycle perspective can provide a better assessment of Canadian public policies in the context of population peaking. It links the changing life cycle patterns brought about by increasing age of entry into the different phases of life and increase in life expectancy to emerging issues related to population peaking, such as recruitment and aging of immigrants or future labour demand and supply by broad skill level. Although most of the paper is theoretical in nature, a short section of it takes an empirical look and contrasts cross-sectional and life cycle estimates of economic dependency ratios for Canadian-born and foreign-born individuals. These estimates are obtained from a dynamic microsimulation model of the Canadian population (LSD-C) that takes into account, among other things, differentials in labour force participation or educational attainment between population groups. The article concludes with suggestions on the most important data gaps that need to be filled to better inform policymaking processes.
\end{abstract}

Keywords: peak population; life cycle perspective; Canada; microsimulation; immigration

\section{Résumé}

Ce papier propose un examen théorique de comment la prise en compte d'une perspective de cycle de vie peut fournir une meilleure évaluation des politiques publiques canadiennes dans le contexte d'une population atteignant un niveau maximal. Il lie les changements engendrés par l'augmentation de l'âge aux transitions entre les différentes phases du cycle de vie et par l'augmentation de l'espérance de vie aux questions émergentes liées à la population atteignant un niveau maximal. Par exemple, on y retrouve une discussion des implications en ce qui concerne le recrutement et le vieillissement des immigrants ou encore l'offre et la demande future de travail selon le niveau de compétence. Bien que la majeure partie de l'article prenne un caractère théorique, une courte section plus empirique présente une estimation des rapports de dépendance économiques pour les Canadiens de naissance et les Canadiens nés à l'étranger, contrastant les évaluations transversales et longitudinales. Ces évaluations sont obtenues à l'aide d'un modèle de microsimulation dynamique de la population canadienne (LSD-C) qui prend en compte, entre autres, les différences entre les groupes de populations au niveau de l'activité sur le marché du travail ou au niveau de la scolarité. L'article conclut avec des suggestions sur les principales lacunes de données qui devraient être comblées afin de mieux informer des politiques.

Mots clés : population maximale, perspective du cycle de vie, Canada, microsimulation, immigration

With industrialization and the expansion of the welfare state, the concept of the life cycle has been traditionally defined as having three phases: childhood, involving education; adulthood, involving work; and old age, involving work incapacity and chronic health problems. In formalizing the phases of the life cycle, it is possible to categorize them in terms of their productivity. School-

1. Centre Urbanisation Culture Société, 385, rue Sherbrooke Est, Montréal, QC H2X 1E3; email: alain.belanger@ucs.inrs.ca. 
age children are net beneficiaries of time and cash transfers, but many of these transfers occur within the family. Elderly adults are also net beneficiaries, but in their case, the largest share of the net flow is from public transfers (especially health care benefits and pensions). During adulthood, labour force participation rates peak, as well as the amount of time devoted to unpaid productive activities such as housework, childcare, and caring for older parents. While women's labour force participation rates have been approaching the higher male rates, females continue to supply most of the unpaid activities, resulting in a net transfer of unpaid production in favour of males.

With the institutionalization of retirement along with the unprecedented life expectancy increases of the 20th century, a new third phase-the golden age-has emerged (Laslet 1989). It falls between adulthood and old age and is characterized by a period of greater leisure.

During the new third age, retired individuals are generally healthy, wealthy, and have more time for non-work activities and personal development. Finally, the new fourth phase corresponds to oldest-old people, characterized by more frailty and dependency than the third age. Next, while production is highly concentrated during adulthood, consumption is much more evenly distributed among the four phases, although it tends to drastically increase in the last years of life due to health care costs and intensive caring time. In consequence, although there are some productive activities during all stages of life, the net transfers are negative during adulthood and positive at other stages.

In the past, age at transition between the different stages of life was clear and fairly stable. Transitions from one stage to another corresponded to normalized and institutionalized age of leaving school, entering the labour force, and retiring. Much of Canadian public policies relate to this normative view of the working life course. As an example, administrative rules of pension entitlements define the normal age for retirement. But the boundaries of these phases are evolving and are becoming increasingly blurred.

\section{Emerging issues}

Two trends are changing the life cycle patterns in Canada and other countries. First, there is a general elongation of the life cycle and of its components, in part due to the major gains in life expectancy during the last century (Vaupel 2010). Educational attainment is also increasing from one cohort to the next, increasing in turn the mean age of entry into the labour force. Then, leaving home, entering into marriage or common-law union, or having a first child are occurring at older ages, consequently delaying the age of entry into adulthood. It might be thought that late entry into the labour force would later translate into late entry into retirement, particularly at a time when life expectancy increase is more and more due to decreased old-age mortality rates. While age at retirement decreased from the 1970s to the mid-1990s, partly because of early retirement incentive programs used as a tool to manage downsizing, people are now delaying retirement and age at retirement has been increasing since 2000 (Carrière and Galarneau 2011). Labour force participation rates at 50 years and over are now clearly moving up, and this trend is expected to continue in the future, due partly to extended education and postponed labour force entry. Recent working life tables show an increase in retirement age that compensates for the increasing life expectancy at older age and thus resulting in stable length of retirement. In addition, trends in life expectancy are expected to increase, albeit at perhaps a slower rate. Changes in healthy life expectancies, however, are less clear. Although the number of healthy years is increasing, it is not clear whether it is increasing faster, at the same rate, or slower than total life expectancy. In any case, the number of years of life lived in poor health or in dependency is also increasing.

Second, globalization, economic restructuring, rapid technological changes, and downsizing firms all tend to modify the traditional single-career path. Over the life course, individuals now have more numerous jobs, often separated by spells of unemployment and underemployment. 
The transition to full retirement is also often preceded by a spell of bridge jobs or part-time jobs. Adult education is not only necessary to increase the skills of workers in their career job, but also for those who are searching for new jobs after layoff.

\section{Recruitment of future immigrants}

These life cycle changes need to be linked with the emerging issue of global population peaking during this century. In this context, the first issue is the effect of global population change on recruitment of future immigrants. Several source countries of current Canadian immigration show declining fertility rates and often even faster population aging than Canada. In the coming decades, China, South Korea, the Philippines, and eventually India will see their labour force population reach a plateau. Similarly to Spain, Italy, or Greece in southern Europe, which changed from countries of emigration to immigration, current source countries for Canadian immigration may well become additional competitors in the global market for labour force and skills. Not only will immigrants become more difficult to recruit, source countries will likely shift to other regions such as northern and sub-Saharan Africa or the Middle East, where the demographic transition is lagging and population growth will continue. This will increase the ethnic diversity of immigrants and might test social cohesion as well as increase the risk of fractionalization. In addition, since the global demand for skilled immigrants will increase when there are more alternative destinations, Canada may need to reduce its selection criteria in order to maintain high immigration numbers.

\section{The aging of immigrants}

Immigrants to Canada are also aging. More than 1.6 million immigrants (about one-third of the total) admitted since 1990 are baby-boomers (born between 1946 and 1966). They expanded the already large cohort of Canadians who are progressively retiring from the labour market and receiving pension transfers and health care services. The immigrant population growth component might therefore increase rather than decrease the pressure on the pension and health care systems, and perhaps add arguments supporting Ponzi-scheme approaches to ever higher immigration as a solution to the aging challenge. While past immigration was largely European, more recent immigrants originate from Asia and other countries, and are therefore more diverse than in the past and more culturally different from the resident population. Adequate knowledge of official language and literacy (Bonikowska et al. 2008), quality of foreign education (Sweetman 2004) and training, and discrimination (Oreopoulos 2011) from potential employers, as well as oversupply of labour during economic downturns are all possible reasons explaining the increasing difficulties that recent immigrants have in fully integrating into the Canadian economy. Despite the high level of educational attainment of recent immigrants, their economic integration is more difficult, and it appears that the economic performance of immigrants admitted since 1990 will not reach the level of the Canadian-born (Picot 2008).

\section{Future challenges}

Marshall and Mueller identified five policy domains where life cycle changes need to be considered (2003): (1) education, transition to employment, and life-long learning; (2) family and the relationship between work and family; (3) work-to-retirement transitions; (4) income security in the later years; and (5) intergenerational relations and social cohesion. In relation with the issue of global population peak, items 1, 3 and 5 are the most likely to be affected, as discussed next. 


\section{Education and employment}

Literacy levels of immigrants in English and French are on average lower than of the Canadian-born, despite higher educational attainment. This difference in English and French literacy explains about two-thirds of the immigrant/Canadian-born earnings gap (Ferrer et al. 2006). Immigrants also face difficulties integrating into the labour market because of language barriers, educational recognition, and discrimination. These factors are correlated with their overall earnings through the life cycle. Therefore, over their lifetime immigrants contribute less than the Canadianborn through the tax system. 2 Changes in the welfare state regulations can modify the level of net transfers over the life cycle and have implications on intergenerational equity. A recent study attempts to create an index of intergenerational justice between older and younger generations for 29 OECD countries3 (Vanhuysee 2013). Canada is ranked fifth from the bottom on intergenerational justice. Given the persistence of intergenerational inequity, there may be more tolerance for inequality in intergenerational transfers when the generations who benefit are the parents or the children of those who overpay. Social cohesion can therefore be in jeopardy when a high proportion of population growth is driven by net immigration rather than natural increase.

\section{Aging and health care}

Even if they benefit from the healthy immigrant effect, aging immigrants will eventually need health care and social support, like older Canadian-born residents do. Continuing changes in the source countries in the context of increasing diversity will increase language barriers and cultural differences here, forcing Canadian health care providers to continuously adapt to an ever changing population. Furthermore, if immigrants live longer than the Canadian-born, can we not then expect lifetime costs for health care and pensions to be higher?

\section{Labour demands and labour supplies}

Increases in the education level of the Canadian-born and arrival of highly educated immigrants is changing the labour supply composition in terms of broad skills (Bélanger and Bastien 2013). In the context of a knowledge society, there will be greater demand for higher skills than lower skills. Nevertheless, the demand for lower-skill jobs will continue to be positive, although at a lower rate. Comparing projections of supply and demand by broad skill levels shows an increasing imbalance in the future, with a large oversupply of highly skilled workers and labour shortages among lower-skilled workers. These forecasts imply an increasing overqualification rate within the labour force, with workers that have higher level of education than job requirements. The Canadian over-qualification rate is already among the highest of all OECD countries (NCES 1997). On this point, a question worth raising for further research is: What are the advantages and disadvantages to Canada of increasing overqualification as concerned productivity or individual satisfaction? Moreover, oversupply of a highly educated labour force and shortages in lower-skilled jobs can influence relative wages by education. Recent studies show that the return from higher education is decreasing at the same time as college and university education costs are increasing (Morissette et al. 2012).

2. In a recent study of the fiscal effects of immigration, Canadian-born households had a net positive balance of $\$ 11,000$ for the 2007-09 period, compared to a net positive balance of $\$ 7,000$ for immigrant households, according to the OECD's International Migration Outlook (2013). Both Canadian-born and immigrant households have net positive taxes minus social transfers, although the net balance is $\$ 3,000$ higher for Canadian-born households. Overall, the OECD study shows that there is a negligible fiscal effect of immigrants in Canada, but this is a cross-sectional analysis.

3. The intergenerational justice index is calculated from indicators such as national debt per child, child and elder poverty, and size of ecological footprint. Canada does poorly on each of the three measures. 
In this situation, will future Canadian generations reduce their investment in human capital? If immigration continues to be highly selective of university graduates, will we increasingly replace the highly skilled labour force with immigrants, while lower-skill jobs are increasingly occupied by the Canadian-born? An alternative would be to be less selective on university education for immigrants (e.g., turning temporary immigrant workers into permanent residents or increase the use of provincial nominees), but this would probably entail more difficulties of linguistic and cultural integration.

\section{Expanding our knowledge base}

\section{Rethinking policies with the life course perspective}

Despite variations in the life course, Canadian policy measures continue to be based on a stereotypical life course pattern of education-work-retirement. More thought is needed to define how social policies can better suit the evolving life course. More research is needed on healthy life expectancy in general, and to determine whether we are facing expansion or compression of morbidity. More research is also needed to understand the full consequences of the changes in life transitions and the diversification of life course patterns. Taking a life course perspective, and knowing that disadvantages tend to cumulate to create larger differences by the end of life, the disadvantages that recent immigrants have over their life course are likely to affect their economic well-being and health at older ages. It is critical to understand how aging affects health care use and costs.

Given the objective of assuring the future economic well-being of the elderly in the context of high immigration, it is also critical to take a life course approach to measure the number of active and inactive years lived in the labour market. Taking a life course approach is better than simply relying on cross-sectional measures, because of the significant differences in age structure of the native and immigrant populations. A cross-sectional perspective creates a bias in favour of the population group with the younger age structure, and it is therefore not surprising that the conventional old age dependency ratio (OADR) is more favourable to immigrants, a population group with a larger share of its population concentrated in the working ages.

This is also important because in Canada the public pension programs (OAS and C/QPP) are not very generous. The replacement rate of public pension is 45 per cent for median earners in Canada, compared to 54 per cent for OECD countries (Bélanger et al. 2016), and thus a large share of the future income of the elderly has to come from their private pension plans or other form of wealth accumulated during their working life. To get a more useful description of the situation, it is preferable to use the economic dependency ratio (EDR) that takes into account the difference in activity rates. The classical (cross-sectional) economic dependency ratio is defined as the ratio between the population not in the labour force (inactive) and the population in the labour force (active). But even when taking differences in participation rate into consideration, differences in age structure can continue to skew the picture. As a better measure, I propose to use the cohort economic dependency ratio (CEDR), which is defined as the ratio between the number of years lived inactive divided by the number of years lived active over the life course. Like other longitudinal demographic measures (cohort life expectancy), it has the inconvenient feature that it can only be observed when the last member of a cohort has died. Fortunately, we can also measure it from simulations.

The LSD-C $C^{4}$ dynamic microsimulation model developed at INRS (Bélanger et al. nd; Sabourin et al. 2017) can be used to estimate the CEDR by projecting until the death of the last individual

4. LSD-C stands for Laboratoire de simulation démographique - Canada. Two other microsimulation models are being developed based on this prototype, one for the United-States (LSD-USA) and one for the European Union (CEPAM-Mic). The author acknowledges the help of his current and past graduate students in the development of the LSD-C microsimulation model: Patrick Sabourin, Guillaume Marois, Samuel Vézina, David Pelletier, Olivier Lafontaine, Kevin D’Ovidio, and Arnaud Bouchard-Santerre. 
of a hypothetical cohort comprised of Canadian-born in a given year or of immigrants admitted in a given year, and calculating the number of person-years lived active and inactive. The model takes into account the increase in life expectancy as well as the increase in older worker labour force participation. It also takes into account differentials in labor force participation or educational attainment between population groups. In the context of current labour market changes (increasing immigration, increasing labor force participation of older workers, differentials in labour force participation of immigrants and by education levels), we take into consideration these characteristics and their plausible evolution. Labour force participation rates vary a lot between education groups; therefore, we compute the economic dependency ratios for the population aged 25 and over, when education is generally completed.

Figure 1 contrasts the two different perspectives of the cohort economic dependency ratios for immigrants and natives. When taking a cross-sectional view, the economic dependency ratio of the Canadian-born is 0.56, meaning that in the observed population (in 2011), the total number of person-years lived inactive represented a little more than half the total number of person-years lived active. In comparison, immigrants present an economic dependency ratio that is only marginally higher (0.59) despite their lower participation rate. Thus, using the cross-sectional approach, their lower activity rate is almost fully compensated by their more favourable age structure. Indeed, we found that when adopting the life course perspective, the dependency ratio doesn't change much for the Canadian-born, but is much less favourable to immigrants. The cohort dependency ratio of Canadian-born is 0.60 , meaning that over his or her lifetime a Canadian-born person can expect to live (beyond age 25) a little bit more than half of a year inactive for each year lived active. The comparable number for a cohort of immigrants is 0.75 .

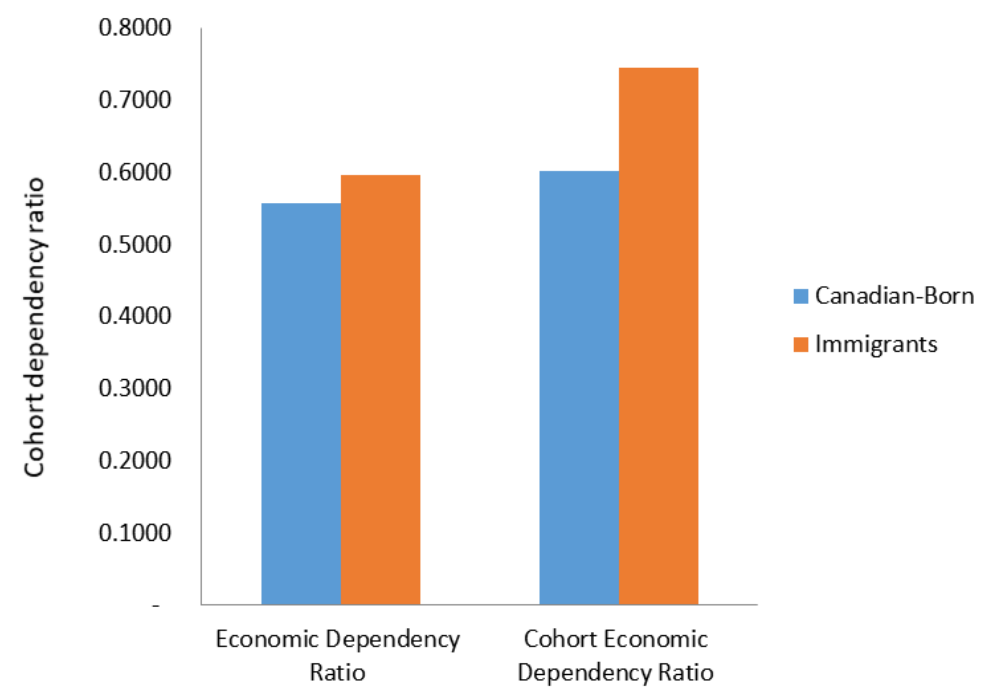

Figure 1: Economic Dependency Ratios for Canadian-born and immigrants under two perspectives, population aged $25+$.

\section{Relation of immigration and fertility levels}

Immigration levels to this country were increased in part to assure continued labour force growth. Is there a relationship between immigration levels and fertility rates? Entry-level Canadian-born and immigrants compete in the labour market, particularly when unemployment rates are high. Increasing the labour force through immigration can create pressure on unemployment rates, particularly among the entry-level age groups. Large immigration intakes would also put pressure on the housing market. Increasing housing costs and unemployment rates may reduce 
the capacity of young families to have the number of children they desire, reducing further the country's natural increase and consequently increasing its dependency on international immigration. This is a topic for further study.

\section{Data gaps}

Another longitudinal survey of immigrants in Canada could help in assessing the progress made since the early 2000s to integrate new immigrants, but longitudinal surveys are expensive. The recent tendency is more toward linkage of existing surveys to administrative data, including landing data of immigrants. In this context, an expansion of the sample size of existing cross-sectional (GSS) and longitudinal surveys (LISA), combined with modification of the sampling frame to provide better estimates through oversampling of target groups such as recent immigrants, could be a more efficient way of filling in data gaps. Facilitating research access to the administrative longitudinal data file and other linked data files in research data centers should be a priority. Surveys similar to the Gender and Generation project conducted in several OECD countries would also be useful to have in Canada. We need to increase our knowledge on the demographic and economic impact of increasing or lowering immigration levels, on the economic integration of youths and immigrants into the labour force, and on public finance in general and health care and pension costs and income taxes paid over the lifetime by immigration status in particular. We lack up-to-date information on intergenerational transfers over the life course.

\section{References}

Bélanger, A., and N. Bastien. 2013. The future composition of the Canadian labour force: A microsimulation projection. Population and Development Review 39:509-25.

Bélanger, A., P. Sabourin, S. Vézina, G. Marois, K. D’ovidio, and O. Lafontaine. nd. The Canadian microsimulation model LSD-C: Content, modules, and some preliminary results. Montreal: Institut national de la recherche scientifique, Urbanisation Culture Société.

Bélanger, A., Y. Carrière, and P. Sabourin. 2016. Understanding employment participation of older workers: The Canadian perspectives. Canadian Public Policy 42(1):94-109.

Bonikowska, A., D.A. Green, and W.C. Riddell (eds.). 2008. Literacy and the Labour Market: Cognitive Skills and Immigrant Earnings. Ottawa: Statistics Canada.

Carrière, Y., and D. Galarneau. 2011. Delayed retirement: A new trend? Perspective on Labour and Income (Catalogue no. 75-001-X):4-16.

Ferrer, A., D. Green, and W.C. Riddell. 2006. The effect of literacy on immigrant earnings. Journal of Human Resources 41(2):380-410.

Laslett, P. 1989. A Fresh Map of Life: The Emergence of the Third Age. London: Weidenfelt and Nicholson.

Marshall, V.W., and M.M. Mueller. 2003. Theoretical roots of the life course perspective, in Social Dynamics of the Life Course: Transitions, Institutions, and Interrelations, edited by W.R. Heinz and V.W. Marshall. New York: Walter de Gruyter.

Morissette, R., G. Picot, and Y. Lu. 2012. Wage growth over the past 30 years: Changing wages by age and education. Economic Insights (Catalogue no. 11-626-X) 8:1-4.

NCES (National Center for Education Statistics). 1997. Adult Literacy in OECD Countries: Technical Report on the First Adult Literacy Survey. Washington: NCES. 
OECD (Organization for Economic Cooperation and Development). 2013. International Migration Outlook 2013. Paris: OECD.

Oreopoulos, P. 2011. Why do skilled immigrants struggle in the labour market? A field experiment with thirteen thousand resumes. American Economic Journal: Economic Policy 3(4):148-71.

Picot, G. 2008. Immigrant Economic and Social Outcomes in Canada: Research and Data Development at Statistics Canada. Analytical Studies Branch Research Paper Series. Ottawa: Statistics Canada.

Sabourin, P., A.Bélanger, S. Vézina, G. Marois, and D. Pelletier. 2017. Immigration, Diversity, Human Capital and the Future Labor Force of Developed Countries: The Canadian Model. 6th World Congress of the International Microsimulation Association. Moncalieri, Turin. 21-23 June 2017.

Sweetman, S. 2004. Immigrant Source Country Educational Quality and Canadian Labour Market Outcomes. Analytical Studies Branch Research Paper Series.

Vanhuysse, P. 2013. Intergenerational Justice in Aging Societies: A Cross-National Comparison of 29 OECD Countries. Available at SSRN: https://ssrn.com/abstract=2309278 or http://dx.doi.org/10.2139/ ssrn. 2309278.

Vaupel, J.W. 2010. Biodemography of human ageing. Nature 464:536-42. 